\title{
PERANCANGAN SISTEM INFORMASI COMPUTER BASED TEST (CBT) BERBASIS WEB DI SMK BANGUN BANGSA MANDIRI KANDANGHAUR
}

\author{
Lilis Emalia ${ }^{1 *}$, Dewi Puspitasari² \\ 1,2 Manajemen Informatika, Politeknik Praktisi Bandung, Bandung, Indonesia \\ *Email: lilis.emalia@gmail.com
}

\begin{abstract}
Abstrak
Penelitian ini bertujuan untuk merancang sistem informasi Computer Based Test (CBT) berbasis web di SMK Bangun Bangsa Mandiri. Metode pengembangan perangkat lunak yang digunakan adalah Waterfall sedangkan bahasa pemrograman yang digunakan dalam implementasi sistem informasi menggunakan XAMPP dan MySQL sebagai database.
\end{abstract}

Kata kunci: Sistem informasi, Computer Based Test (CBT), Web.

\begin{abstract}
This study aims to design a web-based Computer Based Test (CBT) information system at SMK Bangun Bangsa Mandiri. The software development method used is Waterfall while the programming language used in the implementation of information systems uses XAMPP and MYSQL as a database.
\end{abstract}

Keywords: Information system, Computer Based Test (CBT), Web.

\section{PENDAHULUAN}

Dewasa ini teknologi dan internet sudah menjadi bagian dari masyarakat. Seiring dengan berkembangnya teknologi berkembang pula pola pikir manusia termasuk salah satunya untuk mempekerjakan pekerjaan dengan bantuan teknologi. CBT sebagai salah satu metode yang memanfaatkan teknologi dalam penggunaannya yang dikemas sedemikian rupa sehingga efektif dan juga efisien. Computer Based Test (CBT) merupakan salah satu metode yang digunakan untuk pembelajaran dengan memanfaatkan teknologi komputer sebagai medianya yang dikemas secara menarik dan juga interaktif. Sedangkan materi yang disajikan akan berupa jaringan local access fiber. Dengan media transmisi berupa fiber, maka bandwidth yang dibutuhkan semakin tinggi sehingga layanan yang disajikan oleh jaringan lokal fiber inipun semakin banyak, sehingga nantinya jaringan berbasis fiber ini akan menggantikan jaringan tembaga. Dengan bergesernya teknologi jaringan tembaga menuju jaringan berbasis fiber, maka dibutuhkan juga sumber daya manusia yang siap dan mampu khususnya dalam merencanakan dan menggelar jaringan lokal fiber tersebut. Dengan CBT diharapkan akan membantu menciptakan sumber daya manusia yang dibutuhkan serta menjadi salah satu media pembelajaran secara mandiri.

\section{MATERI DAN METODE}

\subsection{Materi}

Dalam penelitian ini terdapat teori yang dipergunakan sebagai referensi dalam menghasilkan sistem yang dirancang, yaitu:

\section{a. Teori Tentang Sistem Informasi}

Krismiaji (2015:15) mengungkapkan "Sistem informasi adalah cara-cara yang diorganisasi untuk mengumpulkan, memasukkan, dan mengolah serta menyimpan data, dan cara-cara yang diorganisasi untuk menyimpan, mengelola, mengendalikan, dan melaporkan informasi sedemikian rupa sehingga sebuah organisasi dapat mencapai tujuan yang telah ditetapkan”.

\section{b. Teori Tentang COMPUTER BASED TEST (CBT)}

Hariyanto (2017:2) mengungkapkan "CBT merupakan tes yang diselenggarakan dengan menggunakan komputer sebagai media utama dalam pelaksanaan kegiatan tes/ujian”.

\subsection{Metode}

Dalam penelitian yang dilakukan terdapat metode pengembangan perangkat lunak yaitu Waterfall. Adapun langkah-langkah yang harus dilakukan pada metode waterfall adalah sebagai berikut:

a. Analisis kebutuhan perangkat lunak

b. Dalam tahapan ini penulis menentukan kebutuhan input berupa kartu ujian, soal ujian, laporan siswa dan lembar jawaban yang dibutuhkan dalam perancangan sistem CBT. 
c. Desain

d. Dalam tahapan ini penulis menentukan mengenai tampilan dalam sistem informasi yang dirancang menggunakan aplikasi balsamiq.

e. Pembuatan kode program

f. Dalam tahapan ini penulis melengkapi kode menggunakan bahasa pemrograman xampp dan database MySQL

g. Pengujian

h. Dalam tahapan ini peneliti menggunakan pihak ketiga untuk melakukan pengecekan secara fungsional.

\section{HASIL DAN PEMBAHASAN}

a. Usecase Diagram

Usecase diagram disajikan pada gambar 1.

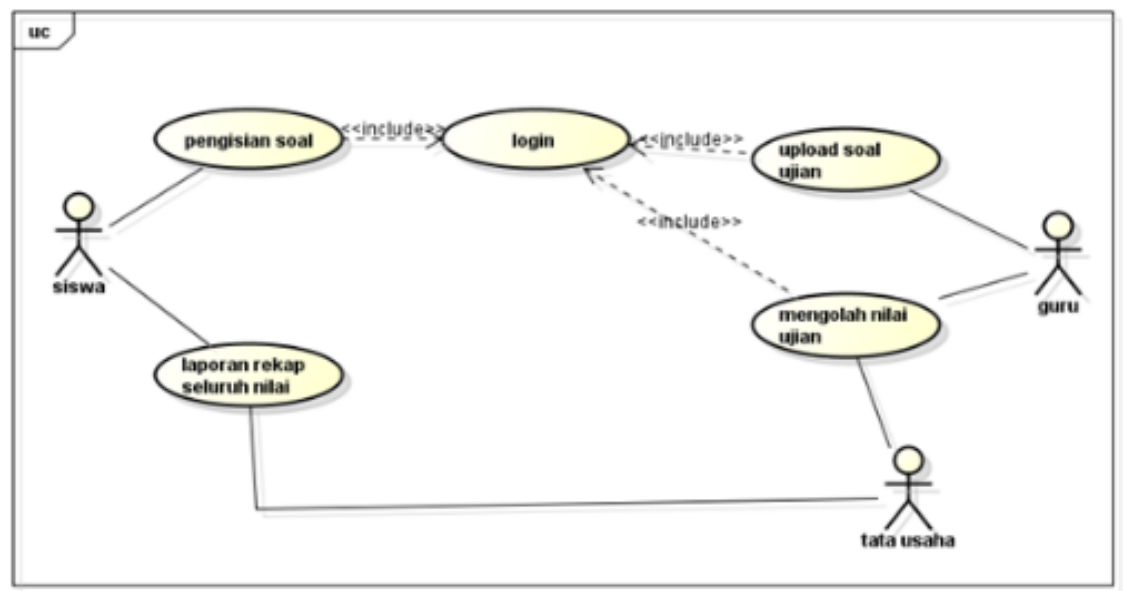

Gambar 1. Usecase Diagram

b. Class Diagram

Class diagram diagram disajikan pada gambar 2.

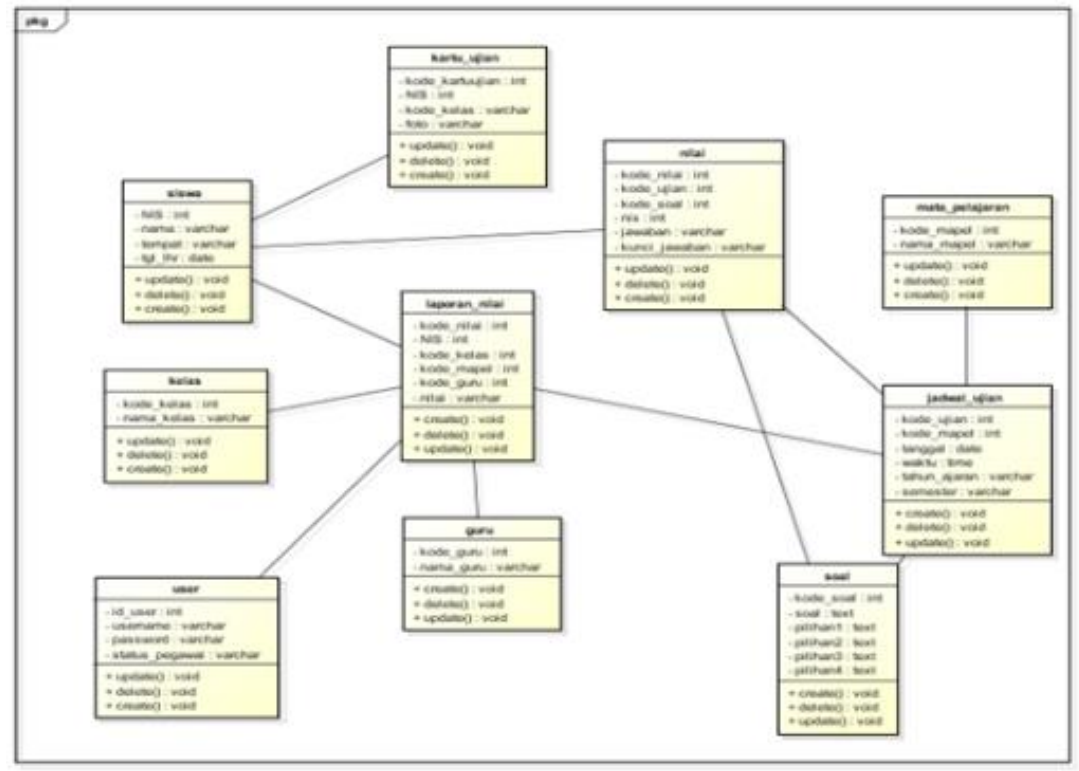

Gambar 2. Class Diagram 
c. Relasi Database

Relasi database disajikan padad gambar 3.

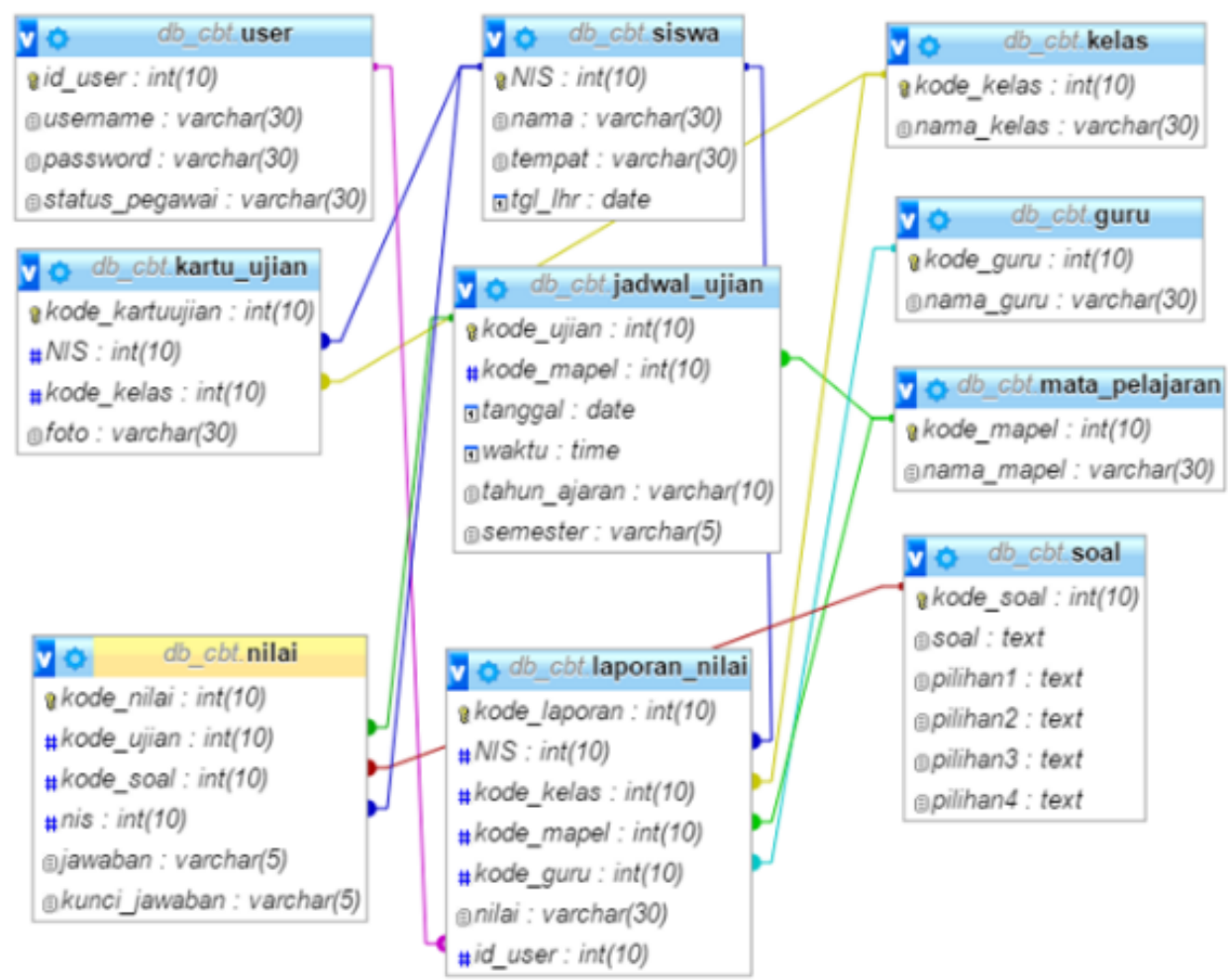

Gambar 3. Relasi Database

d. Tampilan Sistem Informasi CBT

Rancangan input soal disajikan pada gambar 4.

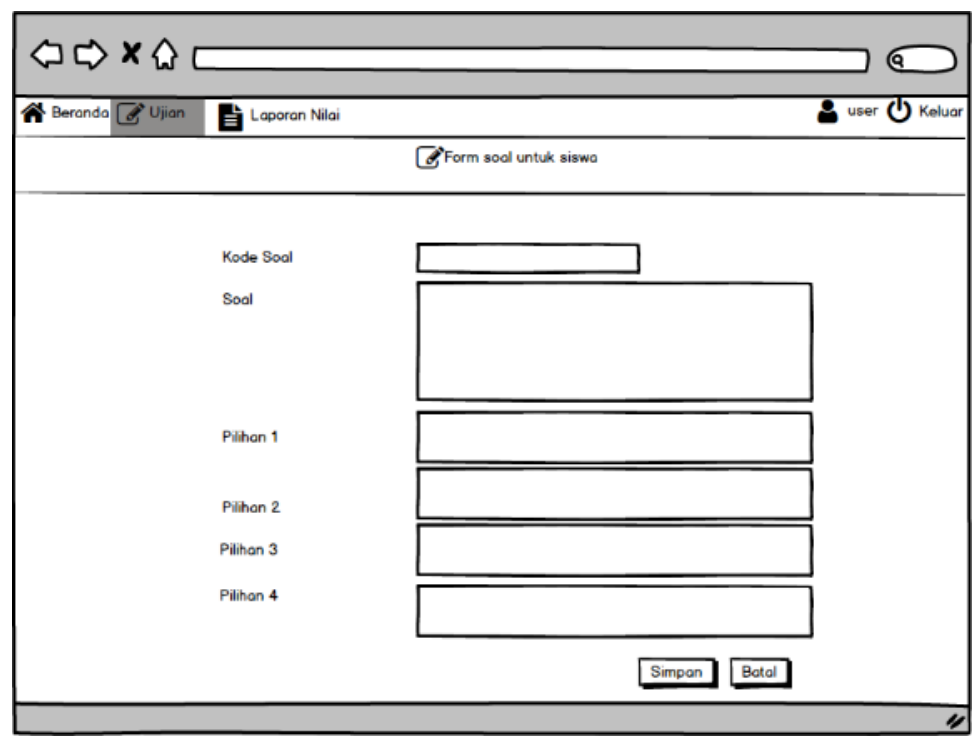

Gambar 4. Rancangan Input Soal 
Rancangan soal CBT disajikan pada gambar 5.

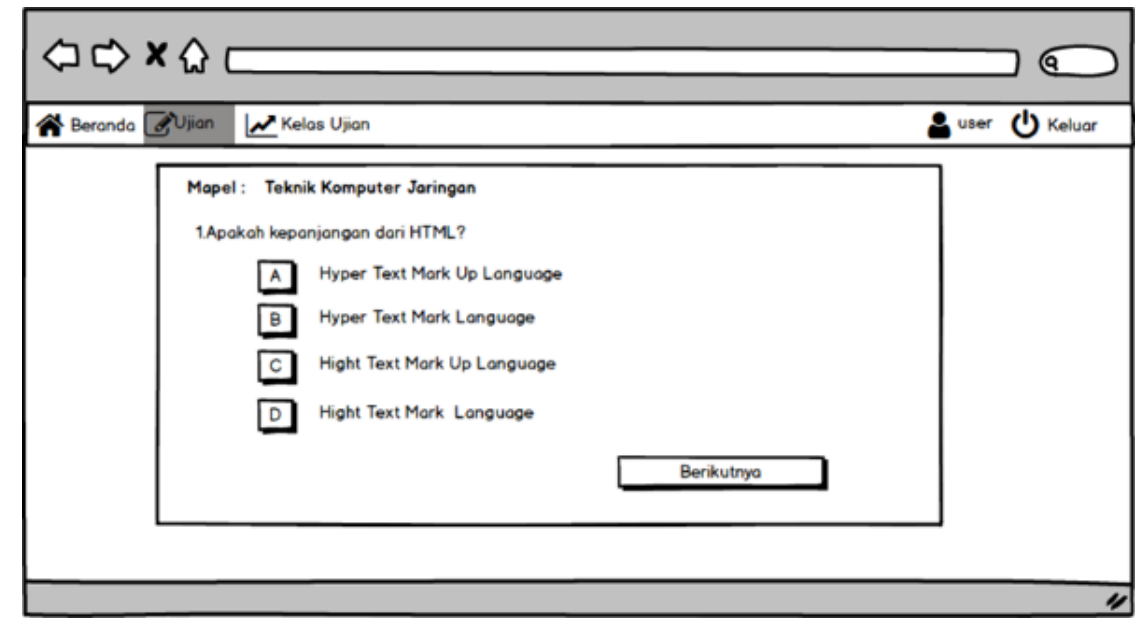

Gambar 5. Rancangan Soal CBT

Rancangan laporan siswa disajikan pada gambar 6.

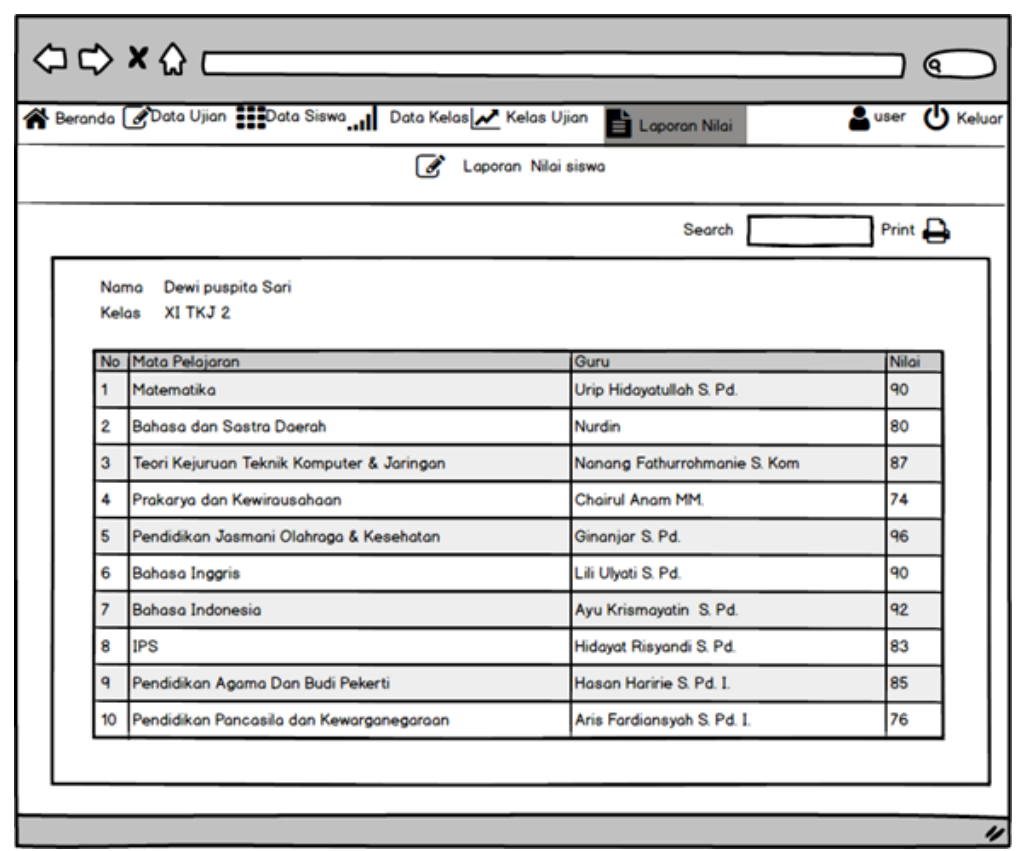

Gambar 6. Rancangan Laporan Siswa

\section{KESIMPULAN}

Berdasarkan hasil pembahasan yang sudah dijabarkan pada BAB sebelumnya dalam perancangan aplikasi Computer Based Test (CBT) berbasis web (studi kasus pada Smk Bangun Bangsa Mandiri Kandanghaur), maka kesimpulan yang dapat diambil sistem ujian selama ini yang kita kenal bersifat konvensional artinya ujian ini dilakukan dengan menggunakan kertas dan pensil,sistem ujian yang bersifat konvensional ini masih memiliki banyak kendala seperti: rawan dalam penyiapan bahan ujian, penggandaan dan distribusi naskah soal, perlu langkah scanning LJK dan scoring,membutuhkan biaya banyak, tenaga, dan waktu. Sehingga menjadikan sistem ujian ini kurang efektif dan efisien. Perkembangan teknologi saat ini sangat pesat sehingga memungkinkan untuk menggunaka ICT dalam ujian. Pemanfaatan teknologi informasi (computer) sebagai salah satu media yang digunakan untuk ujian. CBT ini diharapkan mampu menjawab kendala pada sistem ujian yang masih bersifat konvensional. 


\section{REFERENSI}

1. Ahmar, Ansari Saleh. 2013. Modifikasi Template CMS Lokomedia. Yogyakarta: Garudhawaca.

2. Andriansyah, Doni. 2017. Aplikasi Penerimaan Siswa baru online PDO dan Boostrap. Cirebon: CV Asta Solution.

3. Edgar, Winata dan Johan Setiawan. 2013. Analisis dan Perancangan Prototipe Aplikasi Tracking Bis Universitas Multimedia Nusantara pada Platform Android.ULTIMA InfoSys, Vol. IV, No. 1 Juni ISSN 2085-4579.

4. Hariyanto, Agus.2017. Membuat Aplikasi Computer Based Test dengan PHP, MySQLi dan Boostrap. Yogyakarta:Lokomedia.

5. Kadir, Abdul. 2014. Pengenalan Sistem Informasi Edisi Revisi. Yogyakarta:Andi.

6. Krismiaji. 2015. Sistem Informasi Akuntansi. Yogyakarta: Unit Penerbit.

7. Ladjamudin. 2013. Analisis dan Desain Sistem Informasi. Yogyakarta:Graha ilmu.

8. Laudon, Kenneth C dan Jane P.Laudon. 2014. Sistem Informasi Manajemen. Jakarta:Salemba Empat.

9. Mulyadi.2016.Sistem Akuntansi. Jakarta Selatan:Salemba Empat.

10. Presman, R.S.2015. Rekayasa Perangkat Lunak. Yogyakarta:Andi.

11. Romney, Marshall B. dan Steinbart. 2015. Sistem Informasi Akuntansi. Edisi 13, alihbahasa: Kikin Sakinah Nur Safira dan Novita Puspasari. Jakarta:Salemba Empat.

12. Sadeli, Muhammad. 2013. Dreamweaver untuk orang awam. Palembang: Maxicom. 